\title{
Power and Influence: CEO Power and the Use of Tactical Influence
}

\author{
Abdulaziz Awad Ibn Twalh ${ }^{1}$, Hazaz Abdullah Alsolami ${ }^{2}$, Kenny Teoh Guan Cheng ${ }^{3}$ \& Gazi Md. Nurul Islam ${ }^{4}$ \\ ${ }^{1}$ Iona College, New Rochelle, NY, United States \\ ${ }^{2}$ Putra Business School, Universiti Putra Malaysia, Serdang, Selangor Darul Ehsan, Malaysia \\ ${ }^{3}$ Faculty of Economics and Management, Universiti Putra Malaysia, Serdang, Selangor Darul Ehsan, Malaysia \\ ${ }^{4}$ Tun Abdul Razak School of Government, Universiti Tun Abdul Razak, Jalan Tangsi, Kuala Lumpur, Malaysia \\ Correspondence: Hazaz Abdullah Alsolami, Putra Business School, Universiti Putra Malaysia, Serdang, Selangor \\ Darul Ehsan, Malaysia. E-mail: hazaz22@hotmail.com
}
Received: April 7, 2016
Accepted: May 1, 2016
Online Published: May 5, 2016
doi:10.5430/jms.v7n2p46
URL: http://dx.doi.org/10.5430/jms.v7n2p46

\begin{abstract}
This paper describes how the CEO of an organization can effectively manage the organization by using the identified sources of power, and the various techniques of gaining power in an organization. Often, an organization fails because of insufficient attention paid to how power is managed and deployed. This paper identifies and discusses the power dynamics in organizations, the possible sources of political conflicts at work, and how to solve such issues when they arise. It also discusses the best influence tactics that can be wielded by a CEO to provide guidance, the direction that such influence should take and on which group of people. The authors suggest that the best way to manage employees as a CEO is by becoming a storyteller. This "storyteller" metaphor suggests that CEOs should always focus on creating friendly and interactive environments, rather than tense environments, in which the storyteller (CEO) always engages the audience and makes them feel at ease. It asserts that legitimate and coercive sources of power are no longer advantageous.
\end{abstract}

Keywords: sources of power, power dynamics, influence tactics

\section{Introduction}

This paper has four objectives: the first is to assess the power dynamics of being a CEO in a business organization and to assess the possible sources of political instability in such an organization; the second is to identify the sources of power and the influence skills that can be employed by a CEO for effective management; the third is to elucidate how to use these sources of power to wield influence at work; and the last is to explore effective ways of developing these sources of power. We begin by assessing what it means to be the CEO of a business organization.

Being a CEO comes with prestige and privileges, but it also comes with a number of challenges. In particular, the success of an organization largely depends on the decisions made by its CEO. The CEO's role will be influenced by the magnitude, urgency, capabilities and failings of the organization, and especially the leadership style of the CEO. Aiken et al. (2007) suggest that four key functions collectively define the successful role for a CEO:

1. A CEO should always be the role model for the desired mind-set and behaviour of his/her subordinates. Successful CEOs typically embark on their own personal transformation journey. Their actions encourage employees to support and practice the new types of behaviour.

2. CEOs always relentlessly pursue the goals set by the organization.

3. Building a strong and committed top management team should always be the CEO's top priorities for a given organization.

4. CEOs should always explain clearly the goals and targets of the organization. People will go to extraordinary lengths for causes they believe in, and a powerful transformation story will create and reinforce their commitment. The ultimate impact of the story depends on the CEO's willingness to make the transformation personal, to engage others openly, and to highlight successes as they emerge.

Aiken et al. (2007) view the CEO as the apex of a pyramid and contend that all other members of the organization take their cues from the apex. The authors assert that those CEOs who fail to model the desired mind-sets and behaviour, 
risk failure. The following the section examines how a CEO can effectively use the identified sources of power to influence subordinates without negatively impacting on them, while maintaining respect and friendship within an organization.

\subsection{Sources of Power in Organizations}

Several researchers (for example, Carson, Carson \& Roe, 1993; Finkelstein, 1992; Podsakoff \& Schreisheim, 1985) have identified a number of sources of power, and these have been grouped into five categories; namely: Legitimate, Reward, Coercive, Expert, and Referent Power.

\subsubsection{Legitimate Power}

Legitimate power, sometimes referred to as position power, is a person's ability to influence the behaviour of others because of the position that the person holds in the organization. In many organizations a grading system is used to position an employee, and this establishes his/her legitimate powers. Legitimate power is also evident from the position a person occupies in an organization chart. This type of power has a specific and predetermined range of exercise (Greenberg, 2011). For example, someone who is a project manager in an organization may order his assistant to type the minutes of a meeting but cannot order the assistant to undertake personal work like editing his (the project manager's) postgraduate thesis.

\subsubsection{Reward Power}

A person has reward power if he or she has the potential to influence the actions or behaviours of others because he or she has control over desired resources, such as salary, benefits, human resources, or capital. In other words, it can be defined as a person's ability to influence the behaviour of others by providing them with the things that they desire.

According to Nelson and Quick (2012), reward power can lead to better performance, as long as the employee can see a clear link between performance and reward. An example of this is a higher level of accessibility to company files and data that accompanies a promotion.

\subsubsection{Coercive Power}

Coercive power is the potential to influence others by sanctions or other negative action. Hence, coercive power may be defined as a person's ability to influence the behavior of the others by punishing them or by creating a perceived threat to do so. For example, employees may comply with a manager's directive because of fear or threat of punishment. Consider a teacher who is given a number of hours to teach students, and when he/ she does not teach the given minimum hours, he/she may have his/her salary reduced; or even fired. This kind of power is common in contractual appointments that are renewed depending on performance. Though this kind of power may result in improving the performance of an organization, coercive power has negative side effects and should be used with caution because it tends to result in negative feelings towards those who use it.

\subsubsection{Expert Power}

Expert power is possessed by someone who has a particular kind of expertise or knowledge that other colleagues do not possess. By definition, expert power is a person's ability to influence the behaviour of others because of recognized knowledge, skills, or abilities. For example, a thermonuclear engineer, who possesses expertise in the design of a nuclear power plant that his/her assistant does not possess, holds such power. Experts have power even when they rank relatively low in the organization's hierarchy and they become more important as the company advances (Luthans, 2011). Hence, CEOs face a predicament when they have the authority in an organization, but do not, at the same time, possess the technical expertise to make technical decisions. If such technical expertise is possessed, it is always a strong source of influence in any organization. This is why CEOs often augment their political power with technical expertise.

\subsubsection{Referent Power}

Referent power is created by strong relationships between a leader and his/her followers. It is the potential influence the leader possesses because of trust and affiliation. Lunenburg (2012) defines referent power as a person's ability to influence the behaviour of others because they admire and respect that person: Hence, referent power develops out of admiration for another and a desire to be like that other person. This is the rationale for hiring a celebrity to act as an ambassador for a given cause. This celebrity is hired because of the influence and the admiration he/she has vis-à-vis the public. Researchers (e.g. Craig \& Douglas, 2006; Tosi et al., 2004) have found that a charismatic leader who has strong referent power can inspire an entire organization. 


\subsection{Other Sources of Power}

Kremer and Pustovitovskij (2012) and Astley and Paramjit (1984) have identified other sources of power, and these have been grouped into four categories; namely: Knowledge as Power, Control of Resources as Power, Decision Making as Power, and Networks as Power.

\subsubsection{Knowledge as Power}

Knowledge is the most necessary power resource and it has been found to be indispensable in transforming the structure of power relations (Kremer \& Pustovitovskij, 2012; Astley \& Paramjit, 1984; Kornienko, Kornienko, Fofanov, \& Chubik, 2015). Individuals, teams, groups, or departments that possess knowledge play crucial riles in attaining organizational goals, but only if this knowledge is put to use for the good of the organization. Knowledge power is not unlike expert power (Kremer \& Pustovitovskij, 2012; Astley \& Paramjit, 1984).

\subsubsection{Control of Resources as Power}

Kremer and Pustovitovskij (2012) and Astley and Paramjit, (1984) identified the control of resources as a source of power because an organization needs resources like money, human resources, materials, equipment and customers to function. In other words: "He who controls the resources has power". Departments, groups, or individuals who can provide essential or difficult-to-obtain resources, therefore, naturally possess more power in the organization than others.

\subsubsection{Decision Making as Power}

The authority to make decisions in an organization creates more (or less) power differences among individuals or groups. Hence, managers exercise considerable power in an organization simply because of their authority to make decisions. Although decision making is an important aspect of power in every organization, cultural differences make for some interesting differences in the relationship, in that cultural differences in the role of informal power can somewhat diminish and/or exaggerate power differences.

\subsubsection{Networks as Power}

Kremer and Pustovitovskij (2012) and Astley and Paramjit (1984) demonstrate that power depends not only on access to information, resources and decision making, but also on the ability to secure cooperation in carrying out tasks. Managers who have strong connecting links with others in the organization and beyond, will be more powerful than those who do not possess these links. Being in the centre of a diverse network generates immense power both from the ability to gather knowledge, use early warnings, and distribute resources, as well as from the ability the nexus has to influence others. A case in point is the power generated by social media networks, which is a phenomenon that is still emerging and is not yet well understood.

\section{Using the Sources of Power to Influence Others}

Several researchers have suggested that the principle qualities required by a CEO are to have visions and goals for the organization, to know their own personal strengths and weaknesses, to always strive for excellence, to be willing to go it alone, to embrace resistance, to exemplify corporate values and to always be ethical (Yukl \& Seifert, 2001; Schriesheim \& Hinkin, 1990; Yukl \& Falbe, 1990; Kipnis \& Schmidt, 1988). All values outlined above fall into one of the categories of sources of power discussed above. Of all these skills, to become a leader, credibility should be a strong factor for consideration. A leader cannot influence others if they do not have faith in him or her - i.e. the leader must be trustworthy, sincere and believable. Finding out how the group perceives a person as a leader and the respect they give that person can be of great help in planning how to influence the team members. As a leader, one should always try to eliminate any possible avenues for conflict, and always provide a win-win situation for those engaged in a conflict. This will help create a favorable environment for work.

Some research studies have investigated the direction in which power is used. Throughout the literature of influence behaviour, it has been commonly accepted that influence behaviour is exerted in one of three directions; i.e. upward, downward or laterally. Recent research (Gupta \& Case, 1999) has suggested a fourth direction of influence directed outward; i.e., to those outside one's own organization. The particular influence tactic to be implemented depends on the direction in which influence is intended to have an impact. A study carried out by Kipnis, Schmidt and Wilkinson (1980) indicates that rationality is the most common tactic in upward influence attempts; assertiveness and sanctions are used most often in downward attempts; and upward appeal, exchange of benefits and ingratiation are used in lateral attempts. Obviously, the success of a tactic depends on the receptiveness of the target groups (Yukl, Falbe \& Youn, 1993; Yukl \& Tracey, 1992; Case, Dosier, Murkinson, \& Keys, 1988; Erez \& Rim, 1982; Kipnis, Schmidt \& Wilkinson, 1980). 


\section{Power Dynamics and the Possible Causes of Political Conflict at Work}

Hoffman (1977) defines power as love: impossible to define but easy enough to recognize. Presumably from this definition, power is not a tangible thing that someone can possess, or something that people will look at and fear; rather it is more of a feeling, a recognition, much like love. Dahl (1957) conceptualizes power as "the production of intended effects", suggesting that power has compulsion. However, Goncalves (2012) in his book entitled The Knowledge Tornado, declares that CEOs do not need to instill fear into their employees. He advises that CEOs should always be story tellers for the purpose of creating friendly environments at work. This is echoed by Stevens (2001) in his book Extreme Management: What They Teach at Harvard Business School's Advanced Management Program, He asserts that Goncalves' idea of creating a friendly and interactive environment by CEOs for their employees rather than creating an environment of fear is a leadership imperative.

Power and tactics are, however, open to moderation. According to Negi, 2008, one of the ways of assessing power is to determine which individuals and groups are the most heavily represented on committees and other significant positions. Negi (2008) and Vecchio (2007) also suggest the following moderators: distribution, dependency, uncertainty, compliance, indicators, power determinants, power consequences, and symbols and reputation as the best elements for studying power dynamics in a given organization. Hence, power largely depends on a dependency relationship. If one party (say, A) depends on another (say, B) to execute duties, then B has power over A. In such cases, B will largely determine the success of $\mathrm{A}$ in an organization. CEOs, should keep in mind that they may be enjoying many more benefits compared to their subordinates, but this is a critical dependence and the power dependency is reciprocal. Hence, interdependence is required for the success of the organization and these parties should always be cognizant of each other. Interdependent parties and the relevant differences between them need to be identified. The underlying factors that have created or are reinforcing those differences and how these differences might lead to other assumptions or perceptions are critical to the correct exercise of power. As to the consequences of power, those with the greatest power should be the ones who obtain the most favorable decision outcomes.

CEOs have a great deal of power. In the case of leading by example and character, this type of power is personal power, which should be complemented by coercive power. Coercive power can impart fear in individuals and even reduce the friendliness and the openness of employees towards their bosses; as such, it should always be used with care. Power at work should always be distributed in such a way that it does not destroy the fabric of the organization. For example, a supervisor may be assigned the authority to determine the termination of a contract for any employee without any involvement of the CEO. In such a case, situations may become personal between the supervisor and the employee; hence, however much power may be assigned to a certain individual, supervision is always needed. Another sensitive issue is the indicators of power: job titles, office size and location, special parking privileges, special eating facilities, use of automobiles, airplanes, and office furnishings given to someone are enough to influence power in a given organization. The distribution of such benefits should always be exercised with caution because it can create gaps and conflicts between subordinates and superiors.

Nevertheless, in the workplace, conflicts are an integral part of the environment. However much a CEO may try to create friendly environments, political conflicts are inevitable given the fact that different parties are likely to have different interests. These can greatly reduce the effectiveness of a team and, if not handled properly, can lead to the breakdown of the team. These conflicts should always be handled with caution and resolved quickly because they can exacerbate the conflict.

Conflict between team members comes from several sources. Some conflicts have their basis in behavioral characteristics, while others arise from disagreements about the nature of the team's work and how it can be accomplished. Among the common sources of conflict in an organization that have been identified are the following (from “Common Causes", 2015):

- Team members do not share relevant information with each other: and people may make decisions, or take actions, that others might consider inappropriate or even harmful. Blame and questions about motives can result, creating discord among the team. This is frequently the result of poor communication among the team members.

- Some conflicts develop because the team members fail to follow team norms. A team member creates conflict when he/she displays attitudes or behaviours that go against the team's agreement about how things will be done. For example, if a group norm calls for prompt arrival at meetings and prohibits the use of mobile devices during discussions, ignoring these practices can engender conflict. 
- Conflict can arise when people have mutually incompatible desires or needs. For example, two team members with similar skills may each want a certain assignment to be done differently, thus creating tension.

- Different team members may have different behavioral styles or preferences: individuals may clash over their respective work habits, attention to detail, communication practices, or tone of expression. While these can affect coordination of interdependent tasks, they can especially inhibit direct collaboration among members of a team.

- Members may compete over the limited resources available to accomplish the team's tasks. For example, if two people both rely on the action of a third person to meet identical deadlines, disagreements might arise over whose work should receive priority?

- When some team members are either not contributing their share of effort or not performing at the expected level of quality, the disparities that result can create friction, which may be heightened when critical or highly visible tasks are involved.

- Lack of clarity about tasks, strategies, and/or goals can lead people to make assumptions that others do not share or agree with, which can result in conflict.

However through power and influence, conflicts can be resolved at work. Assigning power at different levels of management can be a solution because managers can exert influence at their respective levels of operation. Managers at higher levels should be cautious in how they delegate power, because this power needs to be utilized in a very prudent manner.

\section{Developing the Sources of Power and Influence Skills That Can Be Employed by a CEO}

Putting power to work without creating fear or conflicts needs tactics to be implemented by the power holder. Researchers suggest that some of the tactics to put power to work without negatively impacting on the subordinates include increasing interpersonal effectiveness, eliminating conflict and inefficiencies by understanding negative or "counter" influence tactics, and learning how to achieve better results by adapting one's style to the preferred methods of others (Yukl \& Seifert, 2001; Schriesheim \& Hinkin, 1990; Yukl \& Falbe, 1990; Kipnis \& Schmidt, 1988).

These same researchers have shown that there are specific behaviors that power holders use to affect others. These influence tactics include the following: Coalition formation by seeking united support from other organizational members; assertiveness tactics by ordering, nagging, setting deadlines, and verbal confrontation with team members; doing favours or offering to trade favours; using flattery and acting friendly; being polite, or humble; using logic, reasoning, planning, and making compromises where necessary; and making formal or informal appeals to organizational superiors for intervention.

The source of power determines what form of influence tactics are can be used to obtain the attention of others. Someone with coercive power might gravitate towards assertiveness; another, with referent power might gravitate toward integration, and someone else with expert power, might try rationality. As discussed in the previous sections about the direction of influence, the use of influence tactics is also dependent upon whom one is trying to influence: subordinates, peers, or superiors. Subordinates are more likely to be the recipients of assertiveness than peers or superiors. On the other hand, exchange, ingratiation, and upward appeals are favoured tactics for influencing both peers and superiors.

From the above it is clear that different sources of power and different forms of expertise can be explored in order for a person to be effective as a CEO. For referent sources of power, an individual's own character is the greatest source of influence. People will always be motivated by the respect the person commands. An example of this is when creating a customer-centric organization, powerful role models help people to see how they personally should make time for the customer in many daily situations. Customer friendly role models can be observed empathising with the customer, taking personal responsibility and making extra effort. One of the ways to develop power is by improving one's level of expertise. Then, one can exert influence by providing with clear logic, an explanation of the benefit, and reassurance that it is the right course of action. In other words, one of the ways to gain respect is possessing knowledge.

Forming close relationships with people and employees is another way of improving effectiveness and developing power as a CEO. Some of the questions that CEOs should ask themselves include; Do your employees enjoy working with you? Do you engender loyalty? Influence can be exerted by appealing to shared values and emotional connections. Social intelligence is another area that should explored by a CEO. The CEO should be able to offer insights into interpersonal issues that interfere with work and help facilitate the resolution of these issues. People should always trust that the CEO will be able to help them. Networking is also very crucial for effectiveness. This should not be a 
matter for the CEO alone, but also for the employees. People need to be frequently in touch with each other to build collaboration so they can seek win-win solutions, unify coalitions and build community. People will trust that they can obtain help from each other and thus become a high performing team that accomplishes objectives. However, above all, a company cannot operate without finances. It is for the CEO to make sure that there is sufficient funding; the control of financial resources is a major source of influence.

Another avenue a CEO can explore to be effective includes communicating clearly. That is, to make sure that he or she has been understood correctly. Similarly, the CEO should always be transparent, with no hidden agendas and should not unnecessarily withhold information; or, if information must be withheld, a clear explanation should always be provided. People respect a sincere attempt at influence and resent being manipulated.

\section{Conclusion}

With increasing competition between organizations for resources such as funds and human resources, successful CEOs/leaders will have to become very engaged with their employees: legitimate and coercive powers no longer hold the edge. The best way to manage employees and create respect as a $\mathrm{C}$ employees $\mathrm{EO}$ is to possess knowledge, provide good examples, maintain a good reputation among employees, and command respect. The working environment should be actively made more friendly, instead of being an environment of fear and panic as in many organizations in the past. Therefore, today's leaders must possess the power of storytelling, the power of charisma and the power of information, in addition to the other predominant types of power that a leader should master. Conflicts at work are inevitable because organizations employ people from different cultural, emotional and skill backgrounds, and with different interests. These differences can frequently lead to conflicts that should be handled quickly and prudently, because conflicts can greatly reduce the effectiveness of the team, create uncomfortable working conditions for some members, and even lead to the failure of the organization. An effective CEO should be able to draw upon an array of different influence tactics, keeping in mind that each tactic has a specific target level or group of people, and a different direction of influence it is best suited for. Finally, a CEO should always be prepared to make an honest self-assessment to see how power and influence can be used most effectively for the benefit of the organization.

\section{References}

Aiken, C. B., \& Keller, S. P. (2007). The CEO's role in leading transformation. Management Quarterly, 48(2), 30-39.

Astley, W. G., \& Paramjit S. Sachadeva. (1984). Structural Sources of Intraorganizational Power: A Theoretical Synthesis. The Academy of Management Review, 9(1), 104-113.

Carson, P. P., Carson, K. D., \& Roe, C. W. (1993). Social power bases: A meta-analytic examination of interrelationships and outcomes. Journal of Applied Social Psychology, 23(14), 1150-1169. http://dx.doi.org/10.1111/j.1559-1816.1993.tb01026.x

Case, T. L., Dosier, L., Murkinson, G., \& Keys, B. (1988). How managers influence superiors: A study of upward influence tactics. Leadership and Organizational Development Journal, 9(4), 25-31. http://dx.doi.org/10.1108/eb053641

Common Causes of Team Conflict. (2014). Retrieved 1 May 2015 from https://www.boundless.com/management/textbooks/

Craig, C. S., \& Douglas, S. P. (2006). International Marketing Research (3rd ed.). New York: Wiley.

Dahl, R. A. (1957). The Concept of Power. Behavioral Science 2(3), 201-15. http://dx.doi.org/10.1002/bs.3830020303

Erez, M., \& Rim, Y. (1982). The relationship between goals, influence tactics and personal and organizational variables. Human Relations, 35(10), 871-878. http://dx.doi.org/10.1177/001872678203501004

Finkelstein, S. (1992). Power in top management teams: Dimensions, measurement, and validation. Academy of Management Journal, 35, 505-538. http://dx.doi.org/10.2307/256485

Goncalves, M. (2012). The Knowledge Tornado (2nd ed.). New York, NY: ASME. http://dx.doi.org/10.1115/1.859957

Greenberg, J. (2011). Behavior in Organizations. Upper Saddle River, NJ: Prentice Hall.

Gupta, S., \& Case, T. L. (1999). Managers' outward influence tactics: An exploratory study. Leadership and Organizational Development Journal, 20(6), 300-311. Irwin. http://dx.doi.org/10.1108/01437739910292616 
Hoffman, M. L. (1977). Moral internalization: Current theory and research. Advances in Experimental Social Psychology, 10, 85-133. Chicago.

Kipnis, D., \& Schmidt, S. M. (1988). Upward influence styles: Relationship with performance, evaluations, salary and stress. Administrative Science Quarterly, 33, 528-542. http://dx.doi.org/10.2307/2392642

Kipnis, D., Schmidt, S. M., \& Wilkinson, L. (1980). Intraorganizational influence tactics: Explorations in getting one's way. Journal of Applied Psychology, 65, 440-452. http://dx.doi.org/10.1037/0021-9010.65.4.440

Kornienko, A. A., Kornienko, A. V., Fofanov, O. B., \& Chubik, M. P. (2015). The nature of knowledge power in a communicative information society. Procedia - Social and Behavioral Sciences 166, 595-600. http://dx.doi.org/10.1016/j.sbspro.2014.12.579

Kremer, J. F., \& Pustovitovskij, A. (2012). Towards a New Understanding of Structural Power. Paper prepared for the International Studies Association Annual Convention 2012.

Lunenburg, F. C. (2012). Power and Leadership: An Influence Process. International Journal of Management, Business, and Administration, 15(1).

Luthans, F. (2011). Organizational behavior (11th ed.). New York, NY: McGraw-Hill

Negi, R. (2008). Power Dynamics in an organization. NSB School of Business B-II/1, MCIE, Delhi-Mathura Road, New Delhi-110044.

Nelson, D. L., \& Quick, J. C. (2012). Understanding organizational behavior (4th ed.). Mason, OH: South-Western/Cengage Learning.

Podsakoff, P. M., \& Schriesheim, C. A. (1985). Field studies of French and Raven's bases of power: Critique, reanalysis, and suggestions for future research. Psychological Bulletin, 97, 387-413. http://dx.doi.org/10.1037/0033-2909.97.3.387

Schriesheim, C. A., \& Hinkin, T. R. (1990). Influence tactics used by subordinates: A theoretical and empirical analysis and refinement of the Kipnis, Schmidt and Wilkinson subscales. Journal of Applied Psychology, 75, 246-257. http://dx.doi.org/10.1037/0021-9010.75.3.246

Stevens, M. (2001). Extreme Management: What They Teach at Harvard Business School's Advanced Management Program. New York City, NY: Warner Business Books.

Tosi, H. L., Misangyi, V. F., \& Fanelli, A. (2004). CEO charisma, compensation, and performance. The Leadership Quarterly, 15(3), 405-420. http://dx.doi.org/10.1016/j.leaqua.2004.02.010

Vecchio, R. P. (2007). Leadership: Understanding the dynamics of power and influence in an organization (2nd ed.). Notre Dame, IN: University of Notre Dame Press.

Yukl, G., \& Falbe, C. M. (1990). Influence tactics in upward, downward, and lateral influence attempts. Journal of Applied Psychology, 75, 132-140. http://dx.doi.org/10.1037/0021-9010.75.2.132

Yukl, G., \& Seifert, C. (2001). Preliminary results from validation research on the extended version of the Influence Behavior Questionnaire.

Yukl, G., \& Tracey, J. B. (1992). Consequences of influence tactics used with subordinates, peers and the boss. Journal of Applied Psychology, 77, 525-535.

Yukl, G., Falbe, C. M., \& Youn, J. Y. (1993). Patterns of influence behaviors for managers. Group and Organization Management, 18, 5-28. 